\title{
Cross-reactive Idiotypes in Immunoglobulin A-deficient Sera
}

\author{
M. K. L. Choung and C. Cunningham-Rundles \\ Memorial Sloan-Kettering Cancer Center and the Cornell University Graduate School of Medical Sciences, \\ Sloan-Kettering Division, Department of Immunology, New York, New York 10021
}

J. Koistinen

Finnish Red Cross Blood Transfusion Service, Helsinki, Finland

\begin{abstract}
Mice of inbred strains immunized with simple antigens can produce antibodies that share similar $V$ regions, which result in serologic similarities called cross-reactive idiotypes (CRI). In this study, we considered the possibility that IgA-deficient humans, who are continuously immunized via the intestinal tract by dietary protein, might also produce antibodies sharing CRI. For this, anti-casein antibodies were isolated from the blood of 16 adult IgA-deficient donors (4 Finns and 12 North Americans) and an autologous anti-anti-casein from the blood of one of the Finnish donors. In addition, a heterologous antianti-casein was raised to the casein-anti-casein immune complexes of this donor. Comparing the activities of the two antiidiotypes, it was found that both bind anti-casein in the region of the antigen binding site, but that each binds additional determinants not located within this region, with the heterologous reagent having more affinity for these latter determinants than the autologous anti-idiotype. Using both reagents in enzyme-linked immunosorbent assay inhibition assays, extensive cross-reactivities between anti-caseins were demonstrated. Using the autologous anti-idiotype, 5 of 16 anti-caseins were found to share CRI, and with the heterologous reagent 12 of 16 shared CRI. In both assays, the anti-caseins of Finnish donors displayed more cross-reactivity than those derived from Northern American donors. These studies show that specific, commonly shared CRI can be identified in this human system in which antibodies are raised as a result of natural immunization across the gastrointestinal mucosa.
\end{abstract}

\section{Introduction}

We have previously shown that an autologous anti-idiotype, an antibody to anti-bovine casein, can be isolated from the sera of patients with selective IgA deficiency (1). About onehalf of individuals having this deficiency can be demonstrated to have an excessive absorption of food protein from the intestinal tract and high levels of antibodies to these substances, presumably due to the absence of secretory IgA (2-3). Further antigen ingestion leads to formation of circulating immune complexes (3-5), and in previous studies we have shown that bovine antigens are important constituents of these complexes

Address correspondence to Dr. Cunningham-Rundles, Memorial SloanKettering Cancer Center.

Received for publication 30 July 1984 and in revised form 14 December 1984.

J. Clin. Invest.

(c) The American Society for Clinical Investigation, Inc.

0021-9738/85/05/1722/07 $\$ 1.00$

Volume 75, May 1985, 1722-1728
(6). Since systemic immunization with antigen-antibody complexes has been shown to be a very effective means of producing anti-idiotypic antibodies in animal systems (7), we previously sought anti-anti-bovine casein antibodies in the sera of IgA-deficient patients. Antibodies with specific activity for the casein binding site of anti-casein antibodies were subsequently isolated (1).

In these studies we show that an autologous anti-idiotype, anti-anti-casein, identifies similar antigenic regions to a specifically raised heterologous anti-anti-casein and that using both reagents, the anti-caseins of unrelated IgA-deficient donors can be shown to share common antigenic determinants that are located both within and outside the antigen binding site.

\section{Methods}

Anti-casein antibodies. Sera or plasma of 16 adult patients with selective IgA deficiency were obtained from the Immunodeficiency Clinic of the Memorial Sloan-Kettering Cancer Center (12 donors) and the Finnish Red Cross (4 donors). Three of the North American donors were related (A., C., and L. Lun); all other donors were unrelated. The serum of a normal male donor $(\mathrm{Geb})$ with a high level of anti-casein antibody was also used. Anti-casein antibodies were isolated from sera by affinity chromatography as previously described (1). Anti-casein IgG was subsequently purified by passage over DEAE cellulose (Bio-Rad Laboratories, Richmond, CA) equilibrated in 0.01 $\mathrm{M}$ Na phosphate buffer, $\mathrm{pH}$ 7.1. This step also removes casein, which is adherent to cellulose under these conditions (1). Anti-casein was evaluated by enzyme-linked immunosorbent assay (ELISA) ${ }^{1}$ (4), and specific anti-casein activity was expressed as $405 \mathrm{~nm} / \mathrm{mg}$ IgG OD. IgG was quantitated by spectrophotometric reading at $280 \mathrm{~m}$ (DU-8; Beckman Laboratories, Irvine, CA) or by ELISA with sensitivity to $0.1 \mathrm{ng}$. The plasma of the IgA-deficient Finnish donor, Rei, having the highest anti-casein activity, was used as a source of anti-casein used in rabbit immunizations and for isolation of an autologous anti-anti-casein. $F\left(a b^{\prime}\right)_{2}$ fragments of Rei anti-casein IgG were prepared by pepsin digestion $(1,8)$; residual $\mathrm{Fc}$ fragments and intact $\mathrm{IgG}$ were removed by absorption with $S$. aureus (1). The purity of the $F\left(a b^{\prime}\right)_{2}$ fraction was tested by electrophoresis on $10 \%$ SDS-polyacrylamide gels.

Isolation of autologous anti-anti-casein. Anti-anti-casein, the autologous anti-idiotype, was isolated from the DEAE-purified IgG fraction of Rei's plasma that did not adhere to casein-Sepharose by a second passage over Sepharose $4 \mathrm{~B}$, to which $1 \mathrm{mg} / \mathrm{ml}$ of Rei anticasein IgG was coupled (1). The adherent fraction was collected by elution of $0.1 \mathrm{M}$ glycine-HCl buffer, $\mathrm{pH}$ 2.7. Anti-anti-casein activity was assayed by an inhibition ELISA (1) as described below.

Preparation of rabbit antisera to anti-casein. Two white male Hartley rabbits were tolerated to pooled human IgG (HIgG) by two intravenous injections of $10 \mathrm{mg}$ (in $1 \mathrm{ml} \mathrm{NS}$ ) of deaggregated pooled HIgG given 3 wk apart (9). The tolerated rabbits were then given 3

1. Abbreviations used in this paper: AP, alkaline phosphatase; CRI, cross-reactive idiotypes; ELISA, enzyme-linked immunosorbent assay; HIgG, human IgG; NPP, p-nitrophenyl phosphate; NS, normal saline. 
i.v. injections of Rei anti-casein-casein immune complexes prepared by incubation of these components at an antigen-antibody ratio of 1 : 10 at $37^{\circ} \mathrm{C}$ for $1 \mathrm{~h}$ and then at $4^{\circ} \mathrm{C}$ overnight. $20 \mu \mathrm{g}$ of anti-casein IgG were used to prepare immune complexes for the first immunization, and $50 \mu \mathrm{g}$ for the immune complexes for the second and third injections given 2 and 4 wk later. The rabbits were bled $3 \mathrm{wk}$ after the last injection. The $50 \%\left(\mathrm{NH}_{4}\right)_{2} \mathrm{SO}_{4}$ precipitated fractions of these sera were absorbed by passage over pooled HIgG and then casein Sepharose affinity columns. Potential antibodies to Rei anti-casein were isolated from fractions not adhering to these columns by a further passage over Sepharose to which Rei anti-casein was attached (1). Antibodies were then tested for anti-idiotypic activity by inhibition ELISA (see below). The antiserum of rabbit 3934, having the highest activity, was used in the following studies.

Assay for autologous and heterologous anti-idiotypic activity. Rei anti-casein [intact or $\mathrm{F}\left(\mathrm{ab}^{2}\right)_{2}$ ] at a concentration of $1 \mu \mathrm{g} / \mathrm{ml}$ in $0.1 \mathrm{M}$ $\mathrm{Na}$ carbonate buffer, $\mathrm{pH}$ 9.6, was used to coat microtiter plates (NUNC, Copenhagen, Denmark) at $37^{\circ} \mathrm{C}$ for $3 \mathrm{~h}$. After washing three times with NS, which contained $0.2 \%$ of Tween-20, $0.1 \%$ carrageenan (Sigma Chemical Co., St. Louis, MO) in $0.1 \mathrm{M}$ carbonate buffer, pH 9.6, was added to the wells to saturate remaining sites. After the coated plates were rewashed three times with NS-Tween-20, increasing amounts of the potential anti-idiotype (autologous [0.001-1 $\mu \mathrm{g} / \mathrm{ml}]$ or heterologous [0.001-100 $\mu \mathrm{g} / \mathrm{ml}]$ or as controls, $10 \mu \mathrm{g}$ pooled HIgG or IgG myelomas or phosphate-buffered saline [PBS]) were added to the appropriate wells, and the plates were incubated at $25^{\circ} \mathrm{C}$ for $5 \mathrm{~h}$. An additional control was the use of $100 \mu \mathrm{g} / \mathrm{ml}$ of a rabbit anti-human anti-tetanus antibody, which was a gift of Dr. R. Geha (10). After washing, alkaline phosphatase (AP)-conjugated casein (see below) was then added, and the $405 \mathrm{~nm}$ OD was read after the addition of $p$ nitrophenyl phosphate (NPP) (1). All experiments were performed in triplicate. As a further negative control, wells were coated with myeloma IgG (see below) instead of Rei anti-casein, incubated with PBS, and then with the AP-casein.

Characterization of anti-idiotype by an antigen competition ELISA. To investigate whether casein could block the binding of anti-casein to the anti-idiotype, antigen-blocking experiments were performed. 100 $\mu \mathrm{l}$ of $\mathrm{Na}$ caseinate (a gift of Dr. $\mathrm{H}$. Farrell) at various concentrations (0.01-100 $\mu \mathrm{g} / \mathrm{ml})$ in PBS-Tween-20, together with $100 \mu \mathrm{l}$ of 1:300 diluted AP-Rei anti-casein (see below), were added to a microtiter plate, the wells of which were coated with autologous anti-anti-casein $(1 \mu \mathrm{g} / \mathrm{ml})$ or the pre- or postimmune rabbit $\mathrm{IgG}(1 \mu \mathrm{g} / \mathrm{ml})$. Plates were coated as described above. After the addition of $\mathrm{Na}$ caseinate and AP conjugate, the plate was incubated for $16 \mathrm{~h}$ at $25^{\circ} \mathrm{C}$. The plate was then washed three times with NS-Tween-20, NPP was added to the wells, and the plates were read at $405 \mathrm{~nm}$ OD. All experiments were performed in triplicate. To some control wells, HIgG or myeloma proteins were added as extraneous antigens; other control wells were coated with myeloma IgG and incubated with the AP-Rei anti-casein. In a further control, wells coated as usual were incubated with PBS, and then the AP conjugate. To calculate the amount of inhibition produced by casein, maximum (100\%) binding was taken as the optical density of the wells not containing casein, and minimum (0\%) binding as the wells coated with PBS. From this the percentage of inhibition for casein could be determined.

Characterization of autologous and heterologous anti-idiotypes by competition ELISA. To determine whether the anti-idiotypes could block each other from binding to Rei anti-casein, cross-inhibition experiments were performed. To wells coated with autologous antianti-casein $(1 \mu \mathrm{g} / \mathrm{ml}), 100 \mu \mathrm{l}$ of heterologous anti-anti-casein $(0.001-$ $1 \mu \mathrm{g} / \mathrm{ml}$ ) and $100 \mu \mathrm{l}$ of 1:300 diluted AP-Rei anti-casein were added and incubated for $16 \mathrm{~h}$ at $25^{\circ} \mathrm{C}$. In the reverse experiment, $100 \mu \mathrm{l}$ of autologous anti-anti-casein $(0.001-1 \mu \mathrm{g} / \mathrm{ml})$ and $100 \mu \mathrm{l}$ of AP-Rei anti-casein were added to wells coated with rabbit anti-idiotype (2 $\mu \mathrm{g} /$ $\mathrm{ml}$ ). As a control, to some wells coated with the autologous anti-anticasein, $1 \mu \mathrm{g} / \mathrm{ml}$ of rabbit anti-anti-tetanus antibody was added instead of the rabbit anti-anti-casein. $10 \mu \mathrm{g}$ of pooled HIgG or various myeloma IgGs were added in some experiments instead of anti-anti- casein as controls. Additional controls used PBS instead of added antianti-casein, or myeloma IgG to coat the wells instead of anti-anticasein. After incubation, all plates were washed three times with NSTween-20, NPP solution was added, and the plates were read as usual. All experiments were performed in triplicate.

\section{Assay for cross-reactivity of anti-casein antibodies}

(a) ELISA. Autologous anti-anti-casein $(1 \mu \mathrm{g} / \mathrm{ml})$ or rabbit anti-anticasein $(10 \mu \mathrm{g} / \mathrm{ml})$ in $0.1 \mathrm{M}$ carbonate buffer were used to coat the wells. The plates were incubated for $3 \mathrm{~h}$ at $37^{\circ} \mathrm{C}$, and then coated with $0.1 \%$ carrageenan as described above. After washing three times with NS-Tween-20, $50 \mu \mathrm{g} / \mathrm{ml}$ of anti-casein IgG isolated from the sera or plasma of 16 IgA-deficient individuals (including Rei), or the anticasein of the normal donor, or a panel of control IgG preparations (see below), or PBS were added to the wells in triplicate and left to incubate for $5 \mathrm{~h}$ at $25^{\circ} \mathrm{C}$. Another control was the use of a myeloma IgG to coat the wells instead of the anti-anti-casein. After washing, AP-Rei anti-casein was added and the incubation was continued for $16 \mathrm{~h}$ at $25^{\circ} \mathrm{C}$. The amount of binding of AP-Rei anti-casein was assayed after the addition of NPP and reading at $405 \mathrm{~nm}$ OD.

In the inhibition ELISA, Rei anti-casein IgG, which produced maximum inhibition, gave the lowest optical density value $(q)$ and the PBS control gave the highest optical density value $(p) .100 \%$ inhibition was assigned to the difference in optical density values between wells containing Rei anti-casein IgG and the PBS control. The percentage of inhibition for other anti-caseins was calculated by substituting this optical density value for the optical density value $q^{\prime}$, in the numerator: percentage of inhibition $=\left(p-q^{\prime}\right) /(p-q) \times 100$.

(b) ${ }^{125}$ I-anti-casein binding studies. $500 \mu \mathrm{l}$ of rabbit anti-anticasein at a concentration of $10 \mu \mathrm{g} / \mathrm{ml}$ in $0.1 \mathrm{M} \mathrm{Na}$ carbonate buffer, pH 9.6, was used to coat NUNC tubes $(1 \times 5 \mathrm{~cm})$ (NUNC); these were incubated for $3 \mathrm{~h}$ at $37^{\circ} \mathrm{C}$. The tubes were then washed three times with NS-Tween-20, recoated with $0.1 \%$ carrageenan, and again washed three times with NS-Tween-20. $500 \mu \mathrm{l}$ of $10 \mu \mathrm{g} / \mathrm{ml}$ of ${ }^{125} \mathrm{I}-$ anti-casein IgG, isolated from the sera or plasma of various IgAdeficient donors or the same amounts of ${ }^{125} \mathrm{I}-\mathrm{HIgG}$ or ${ }^{125} \mathrm{I}$-myeloma proteins, were added to the tubes. These were incubated for $16 \mathrm{~h}$ at $25^{\circ} \mathrm{C}$ and the total amount of radioactivity was then determined by a gamma scintillation spectrometer (Packard Instrument Co., IL). The tubes were then washed three times with NS-Tween-20 and the remaining radioactivity was measured. The percentage binding for each iodinated anti-casein IgG or other IgG was calculated from the amount of radioactivity before and after washing. Rei anti-casein IgG, which gave the highest value in the binding study, was extrapolated to $100 \%$ and the PBS control which gave the lowest binding was assigned $0 \%$; from these the percentage of binding for other ${ }^{125} \mathrm{I}$-anti-caseins or IgG preparations was calculated.

Iodination of anti-caseins and IgG preparations. $100 \mu \mathrm{g}$ of anticasein IgG, HIgG, or myeloma IgG in $250 \mu \mathrm{l}$ of $0.05 \mathrm{M}$ phosphate buffer, pH 7.0, was mixed with three iodo beads (Pierce Chemical Co., Rockford, IL) at $0^{\circ} \mathrm{C}$. To this, $50 \mu \mathrm{l}$ of $\mathrm{Na}{ }^{125}$ iodide (New England Nuclear, Boston, MA) at an activity of $20 \mathrm{Ci} / \mathrm{ml}$ was added; and the reaction was continued at $0^{\circ} \mathrm{C}$ for $3 \mathrm{~min}$. After the reaction was stopped, unbound ${ }^{125} \mathrm{I}$ was removed by extensive dialysis vs. $0.1 \mathrm{M}$ phosphate buffer, pH 7.0. The final specific activity of anti-casein and IgG preparations was between 1 and $4 \mu \mathrm{Ci} / \mathrm{mg}$.

\section{Alkaline phosphatase conjugates}

(a) Alkaline phosphatase-labeled anti-casein. Rei anti-casein IgG was coupled to AP at an enzyme protein ratio of 1:2 (1). The enzymecoupled antibody was then collected in the void volume of a $0.2 \times 6$ cm column of Ultragel ACA 34 (LKB-Produkter, Bromma, Sweden). The conjugate was diluted in PBS containing $1 \mathrm{M}$ glycine to block residual gluteraldehyde groups and the optimum dilution, 1:300, was used in all experiments. In separate ELISA experiments, 81.8, 72, and $60.4 \%$ of this conjugate retained the ability to bind to $\mathrm{Na}$ caseinate, autologous, or heterologous anti-anti-caseins (respectively) bound to polystyrene. 
(b) Preparation of alkaline phosphatase-labeled casein. Purified Na caseinate was coupled to AP at an enzyme protein ratio of 1:2 (1). The aggregates were collected in the void volume from an Ultragel ACA 22 column. The conjugate was then used at a dilution of 1:100 in PBS-Tween 20.

Immunoglobulin fractions. Myeloma proteins $\mathrm{Chr}\left(\operatorname{IgG}_{1}, \kappa\right)$, Fre $\left(\operatorname{IgG}_{1}, \lambda\right)$, Bau $\left(\operatorname{IgG}_{2}, \kappa\right)$, Gui $\left(\operatorname{IgG}_{2}, \lambda\right)$, Hac $\left(\operatorname{IgG}_{3}, \kappa\right)$, Jor $\left(\operatorname{IgG}_{3}, \lambda\right)$, and $\mathrm{Pen}\left(\mathrm{IgG}_{4}, \kappa\right)$ were gifts from Dr. G. Litman. The $\mathrm{IgG}$ fraction of pooled human gammaglobulin (Gamastan, Cutter Laboratories, Berkeley, CA) was purified by passage over DEAE cellulose and equilibrated in $0.01 \mathrm{Na}$ phosphate buffer, $\mathrm{pH} 7.1$ (11). The IgG fraction was extensively dialyzed vs. water, lyophilized, and reconstituted in PBS at $10 \mathrm{mg} / \mathrm{ml}$. IgG aggregates were removed by centrifugation at $1,000 \mathrm{~g}$ (IEC-PRJ, Damon, PA) at $4^{\circ} \mathrm{C}$ for 10 minutes. The deaggregated portion was removed from the top third of the supernatant. This material was used for tolerization of rabbits to $\mathrm{HIgG}$ and as a control in all experiments. Quantitation of IgG was determined by spectrophotometric readings at $280 \mathrm{~nm}$ OD using extinction coefficient of 1.2 or by ELISA with sensitivity to $0.1 \mathrm{ng} / \mathrm{ml}$.

\section{Results}

Anti-idiotypic activity of autologous anti-anti-casein. The antiidiotypic activity of potential anti-anti-caseins isolated from Rei serum was determined by inhibition ELISA (1). As shown in Fig. 1, addition of increasing amounts of autologous (Rei) anti-anti-casein $\mathrm{IgG}(0.001-1 \mu \mathrm{g} / \mathrm{ml})$ inhibited progressively the binding of AP-casein to both intact and $F\left(a^{\prime}\right)_{2}$ fragments of Rei anti-casein IgG. Pooled human HIgG or several myeloma proteins did not inhibit the binding of AP-casein to Rei anticasein. Noncoated wells (PBS) or wells coated with myeloma IgG produced no absorbance.

Anti-idiotypic activity of rabbit anti-anti-casein. As in the above ELISA, increasing amounts of the rabbit anti-idiotype also increasingly blocked the binding of AP-casein to both intact (Fig. $2 A$ ) and $\mathrm{F}\left(\mathrm{ab}^{\prime}\right)_{2}$ fragments (Fig. $2 B$ ) of Rei anticasein IgG. The preimmune serum was not inhibitory in either case. As for the autologous anti-idiotype, pooled HIgG failed to inhibit the binding of AP-casein to either intact or $\mathrm{F}\left(\mathrm{ab}^{\prime}\right)_{2}$ fragments of Rei anti-caseins. Additionally, the use of a heterologous anti-anti-tetanus antibody did not prevent the binding of AP-casein to intact anti-casein; noncoated wells (PBS) or wells coated with myeloma IgG produced no absorbance.

Characterization of anti-idiotype by antigen competition ELISA. In the above ELISA, the anti-idiotype could block casein from binding to anti-casein. Inversely, to determine

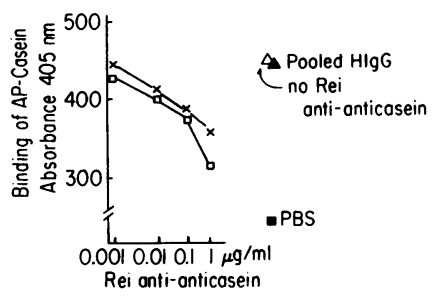

Figure 1. An inhibition ELISA was used to determine the anti-idiotypic activity of the autologous anti-anti-casein. As the concentration of autologous Rei anti-casein IgG increased, less AP-casein was bound to intact $(-x-)$ and $F\left(a b^{\prime}\right)_{2}(-\square-)$ fragments of

Rei anti-casein IgG, which coated the wells. $10 \mu \mathrm{g}$ of $\mathrm{HIgG}$ or the same amount of various myeloma proteins did not inhibit this reaction. The negative control (PBS but no anti-idiotype) is also shown. The absorbance ( $405 \mathrm{~nm}$ ) of the PBS-coated well was $<100$. When wells were coated with myeloma IgG, no binding of AP-casein occurred (absorbance $<100$ ). The relative binding is indicated by absorbance at $405 \mathrm{~nm}$.
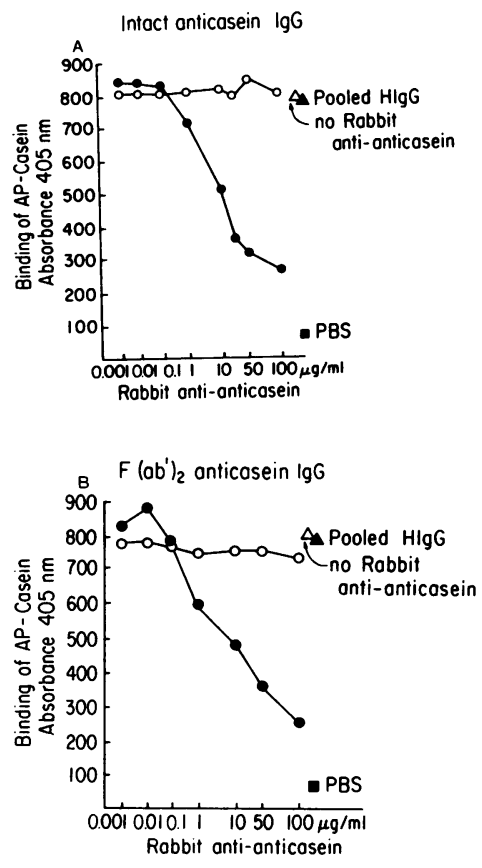

Figure 2. The presence of anti-idiotypic activity is demonstrated by the use of an inhibition ELISA. The IgG fraction of rabbit postimmune serum (heterologous anti-anti-casein) (- - -) progressively blocks the binding of APcasein to intact Rei anti-casein $\operatorname{IgG}(A)$ and $\mathrm{F}\left(\mathrm{ab}^{\prime}\right)_{2}$ fragments of Rei anti-casein IgG $(B)$. Rabbit preimmune IgG (-O-) and 10 $\mu \mathrm{g}$ of pooled HIgG or various myeloma proteins failed to block AP-casein from binding to intact $(A)$ or $\mathrm{F}\left(\mathrm{ab}^{\prime}\right)_{2}$ fragments $(B)$ of Rei anti-casein IgG. In a further control, purified rabbit anti-tetanus antibody also produced no blocking of AP-casein binding to intact Rei anti-casein (results same as the preimmune serum). The amount of binding is indicated by the absorbance of $\mathbf{4 0 5} \mathrm{nm}$. For each, the negative control (PBS but no anti-anti-casein $[\Delta]$ ) is given, and the absorption for wells coated with PBS alone ( $\square$ ). Wells coated with myeloma IgG produced an absorbance $<100$.

whether casein could block the binding of anti-casein to autologous or heterologous anti-anti-casein, an antigen competition assay was devised in which the antigen and AP-Rei anti-casein were added simultaneously. As shown in Fig. 3, $A$ and $B$, additions of increasing amounts of sodium caseinate increasingly blocked the binding of AP-Rei anti-casein to the autologous and heterologous anti-idiotypes. At a concentration of $100 \mu \mathrm{g} / \mathrm{ml}$, casein could inhibit $71 \%$ of binding between the anti-casein and the autologous anti-idiotype, while for the heterologous anti-idiotype this reaction could only be inhibited by $48 \%$. Extraneous antigens, such as myeloma proteins or pooled human gammaglobulins, did not block this binding, even at a concentration of $1 \mathrm{mg} / \mathrm{ml}$. Uncoated wells (PBS) or wells coated with myeloma IgG produced an absorbance of $<100$.

Characterization of autologous and heterologous anti-idiotypes by competition ELISA. A competition ELISA in which the rabbit anti-idiotype was permitted to block the autologous anti-idiotype, or the autologous anti-idiotype to block the heterologous anti-idiotype, from binding to AP-Rei anti-casein was used to determine if the autologous or heterologous antiidiotypes recognized similar or different determinants on Rei anti-casein. As shown in Fig. 4, additions of increasing amounts of autologous anti-anti-casein $(-\times-)$ progressively blocked the binding of AP-Rei anti-casein to wells coated with heterologous anti-anti-casein; likewise, as the amounts of heterologous anti-anti-casein (- - - ) increased, progressive inhibition of the binding of Rei anti-casein to autologous anti-anticasein was also observed. (For the plates coated with $2.0 \mu \mathrm{g} /$ $\mathrm{ml}$ heterologous anti-idiotype, greater binding of the AP-Rei anti-casein conjugate was observed than for those coated with $1.0 \mu \mathrm{g} / \mathrm{ml}$ autologous anti-idiotype.) As a control, the rabbit anti-anti-tetanus antibody $(1 \mu \mathrm{g} / \mathrm{ml})$ was tested as an inhibitor 

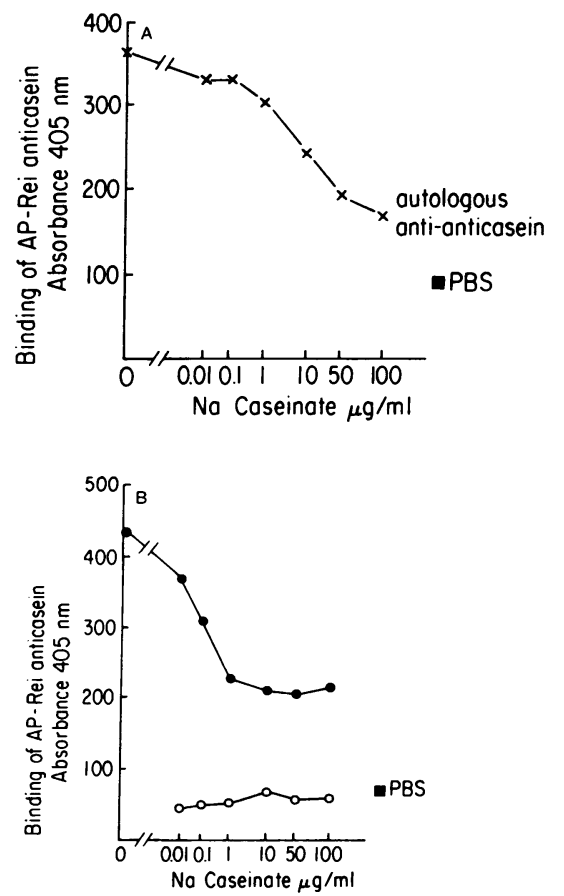

Figure 3. Increasing concentrations of $\mathrm{Na}$ caseinate progressively blocked the binding of AP-Rei anti-casein to the autologous antianti-casein IgG $(A)(-\times-)$ and to the rabbit anti-anti-casein IgG (B) (- - -). The binding of AP-Rei anti-casein to rabbit preimmune IgG (-O -) was comparable with that of the PBS control $(B)$. (PBS controls were wells in which there was no anti-anti-casein coat.) The amount of binding of AP-Rei anti-casein is reflected by the absorbance of $405 \mathrm{~nm} .1 \mathrm{mg} / \mathrm{ml}$ pooled human IgG or various myeloma proteins had no effect upon the binding of AP-Rei-anticasein to the autologous or heterologous anti-idiotype. Wells coated with myeloma IgG produced absorbance of $<100$.

of the binding between the autologous anti-anti-casein and the AP-Rei anti-casein; inhibition was not observed. Pooled human HIgG failed to inhibit the binding of AP-Rei anticasein to either anti-idiotype. As above, uncoated wells or wells coated with myeloma IgG produced an absorbance of $<100$.

\section{Cross-reactivity of anti-casein antibodies}

(a) ELISA. To test the possibility that antigenic cross-reactivity might exist between the anti-casein antibodies of different IgA-

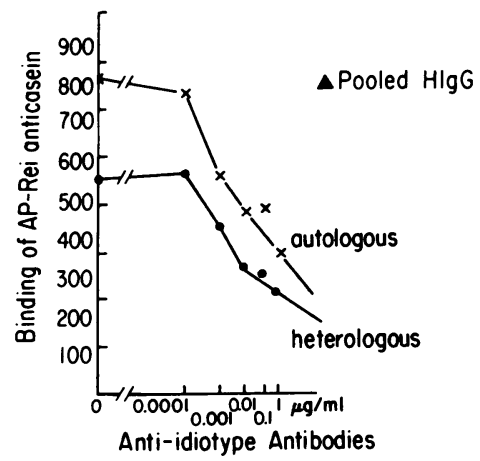

Figure 4. In a competition ELISA, AP-Rei anti-casein bound progressively less to the autologous anti-anti-casein with the addition of increasing amounts of heterologous anti-anti-casein (- - -). Similarly, AP-Rei anti-casein was progressively prevented from binding to the heterologous anti-anti-casein as increasing amounts of autologous anti-anti-casein $(-x-)$

were added. Additions of $1 \mu \mathrm{g} / \mathrm{ml}$ rabbit anti anti-tetanus antibody failed to block the binding of AP-Rei anti-casein to either antiidiotypes. Wells coated with myeloma IgG produced absorbance of $<100$. deficient donors, we determined the degree of inhibition a panel of isolated anti-caseins produced on the binding of APRei anti-casein to either autologous Rei-anti-anti-casein or rabbit anti-anti-casein. For these experiments, equal amounts of isolated anti-casein IgG of the 17 donors were used.

The results for experiments using the autologous anti-anticasein are shown in Fig. $5 \mathrm{~A}$ and that for heterologous antianti-casein in Fig. $5 B$. For each anti-casein IgG, the relative amount of inhibition produced was expressed as a percentage of the inhibition produced by nonlabeled Rei anti-casein IgG, which in both experiments was found to produce maximum inhibition. The PBS coated tubes produced very low absorbance, which was similar to the results for wells coated with four myelomas or pooled human IgG. Of the sera tested, Kar, Tap, Rei, and Ket were from donors of Finnish ancestry; the remaining sera were derived from North American donors of diverse ancestry. In the assay using the autologous anti-anticasein (Fig. $5 \mathrm{~A}$ ), anti-caseins of the Finnish sera, Kar and Ket, and those of the Americans (Nat and Lau) produced significant inhibition ( $>50 \%$ ), while the remaining anti-caseins, including that of Geb, the normal donor, produced $<50 \%$ inhibition.

Using the heterologous anti-anti-casein, anti-casein IgG from the sera of Ket, Lau, Kar, Tap, and Wei inhibited by $75 \%$ or more the binding of Rei anti-caseins to the rabbit antiidiotype. Of these, Ket, Kar, and Tap were Finnish donors. An intermediate level of inhibition (50-75\%) was found for the anti-caseins of Ier, Ruf, Win, Gaf, Nat, and McK, while anti-caseins from C. Lun, L. Lun, Sil, and A. Lun, and Geb (the normal donor), produced $<50 \%$ inhibition.

In Fig. 5, both $A$ and $B$, successful tolerization of the rabbit to pooled human HIgG was demonstrated by a lack of reactivity of the rabbit anti-anti-casein to pooled HIgG or four classes of IgG myelomas with $\kappa$ or $\lambda$ light chains.

(b) ${ }^{125}$ I-anti-casein antibody binding studies. To test for cross-reactivity by a direct binding study, equal amounts of ${ }^{125}$ I-anti-casein IgG of nine different IgA-deficient donors were added to NUNC tubes coated with rabbit anti-anti-casein. In agreement with the ELISA, Fig. 6 shows a high percentage of binding (93-100\%) for the anti-caseins of Rei, Lau, Kar, and Ket; an intermediate level of binding (69-73\%) for those of Tap and Nat; and $<50 \%$ binding for those of A. Lun, C. Lun, and L. Lun. Again, the anti-caseins of the four Finnish donors exhibited greater binding to the heterologous anti-idiotype than anti-caseins of other donors. Iodinated pooled HIgG and myeloma IgG bound in insignificant amounts to the rabbit anti-anti-casein, which again reinforced the view that this reagent is directed at idiotypic determinants of anti-caseins.

(c) Relationship of inhibition to anti-casein activity. To determine if the degree of antigenic cross-reactivity was related to the anti-casein activity of the antibody, these parameters were compared using the Pearson correlation. The resulting values, 0.402 and 0.136 , using autologous and heterologous anti-idiotypes, respectively, showed no significant relationship to exist.

\section{Discussion}

In these studies, an autologous anti-anti-casein was isolated from the serum of an IgA-deficient donor, Rei, and a heterologous anti-anti-casein was raised by immunization of rabbits 
Anticosein IgG of IgA

deficient donors:

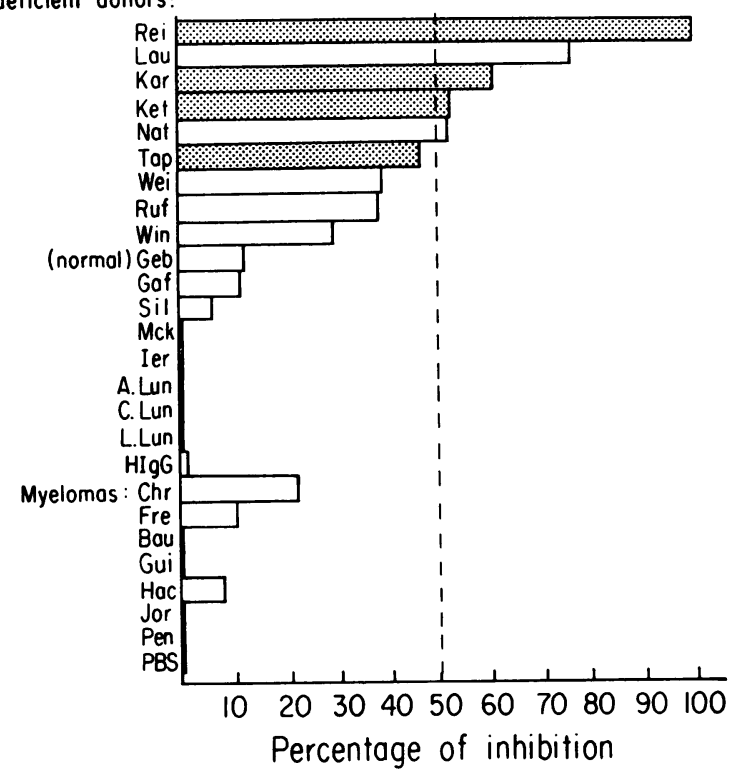

Figure 5. The percentage of cross-reactivity between various anticaseins was determined by an inhibition ELISA in which $10 \mu \mathrm{g}$ of these anti-caseins (or the same amount of the control IgG preparations) were permitted to interfere with the binding of AP-Rei anticasein and its corresponding autologous $(A)$ or heterologous $(B)$ antianti-caseins. Maximum inhibition occurred with the addition of Rei

with the anti-casein of this donor, in complex with casein. Using these reagents we show that anti-casein antibodies of unrelated IgA-deficient individuals share several cross-reactive idiotypes (CRI), and that these CRI are particularly characteristic of Finnish IgA-deficient donors.

To investigate the nature of the binding of the autologous

Anticasein IgG of IgA

deficient donors :

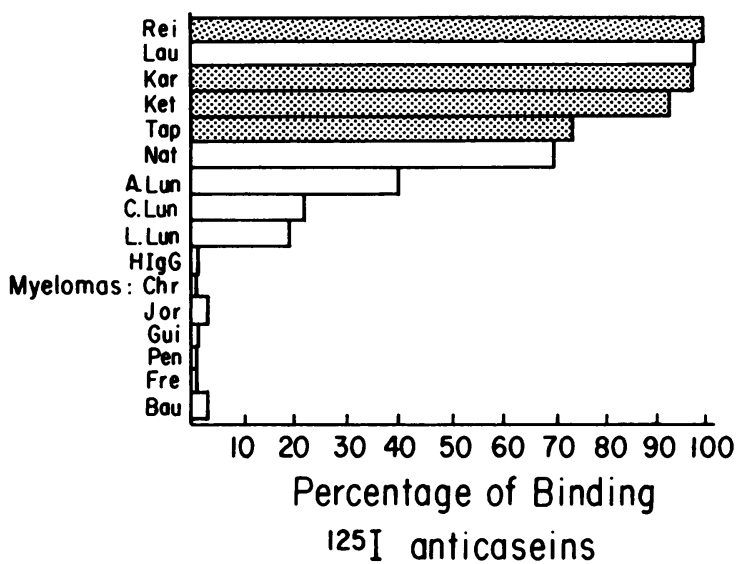

Figure 6. The relative affinity of nine ${ }^{125} \mathrm{I}$ anti-caseins for the heterologous anti-idiotype was determined in a direct binding experiment in which anti-caseins were permitted to bind to heterologous anti-idiotypic coated tubes. Included as controls were pooled HIgG and six myeloma proteins. Shaded anti-caseins were derived from blood of Finnish donors.

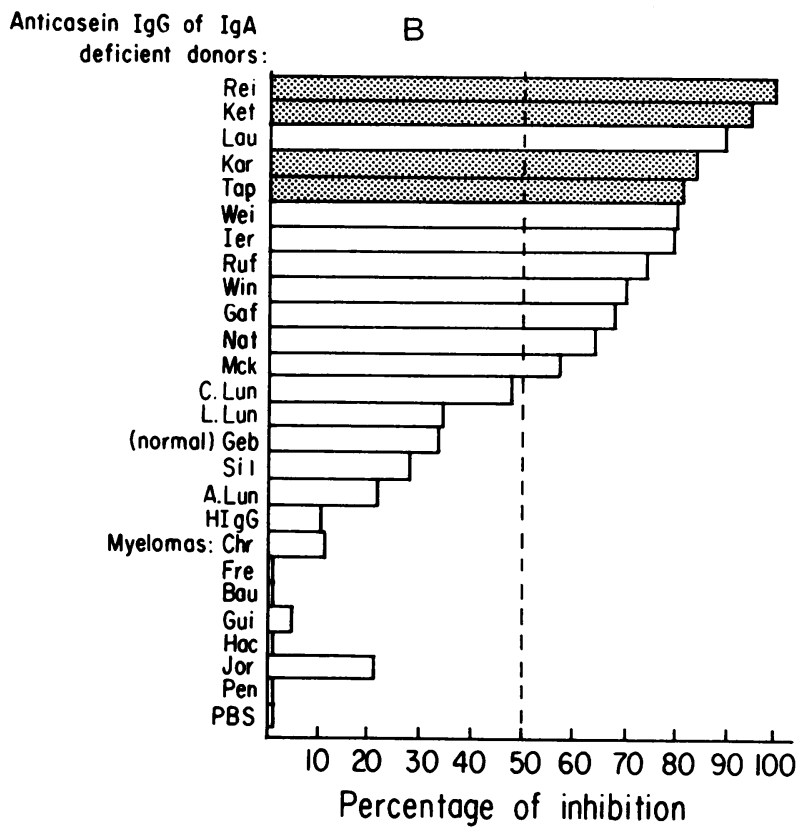

anti-casein and no inhibition by the PBS control. Anti-caseins of all donors are given as three initials of the last name. Anti-casein of normal donor Geb was included as well as pooled HIgG and seven myelomas of different isotype. Significant inhibition was considered $50 \%$ or greater. Shaded anti-caseins were derived from blood of Finnish donors. Inhibition was calculated as described in the text.

and heterologous anti-idiotype to anti-casein, we found that both the isolated autologous anti-anti-casein and the rabbit anti-anti-casein bound either intact or $F\left(a b^{\prime}\right)_{2}$ fragments of Rei anti-casein in the region of the antigen-binding site, since they prevented the binding of casein to anti-casein. In addition, the finding that both the autologous and heterologous antiidiotypes compete with each other for binding to anti-casein, demonstrates that the determinants they recognize may be similar, although the effects of steric hindrance in this experiment make it impossible to draw firm conclusions. In the antigen competition assay, casein appeared to block more completely the binding of anti-casein to the autologous antiidiotype than to the heterologous anti-idiotype, which implies that a greater number of nonsite-directed antibodies could be present in the heterologous as opposed to the autologous antisera. This is in agreement with murine studies that show that a higher proportion of nonsite-directed vs. site-directed anti-idiotypes are produced when the immunizing antibody is more saturated with antigen (12). These differences might be due to immunization, since the heterologous anti-idiotype was prepared by immunization with immune complexes at an antibody/antigen ratio of 1:10, and the autologous anti-idiotype was isolated from the serum of an IgA-deficient individual who has a variable saturation of anti-casein with casein (depending on diet, references 4 and 5). Another reason for the inability of casein to block completely the interaction between idiotype and the anti-idiotype could be the presence of antibody to nonidiotypic determinants in the autologous and heterologous anti-idiotypes. Such antibodies could be directed at framework, hinge, or other $\mathrm{F}(\mathrm{ab})$ determinants. This possibility seems less likely since neither the autologous nor the heterol- 
ogous anti-idiotypes bound pooled human IgG or a panel of various myeloma proteins. In addition, the use of a nonrelevant rabbit anti-idiotype anti-anti-tetanus produced no effects in these experiments.

Using these anti-idiotypes in an assay used to identify CRI between the isolated anti-caseins of unrelated and ethnically diverse IgA-deficient donors, we found that 6 of 16 were crossreactive using the autologous anti-idiotype, and that the same six, plus an additional six anti-caseins, were cross-reactive using the heterologous anti-idiotype. These findings indicate that anti-caseins share several common idiotypes, with the rabbit antisera having the capacity to recognize a broader spectrum of cross-reactive determinants than the autologous anti-anti-casein. For the reasons discussed above, it is not possible to exclude completely the possibility that some of the determinants recognized (particularly by the heterologous group) may be nonidiotypic, but the inability of pooled human IgG, or six IgG myelomas of various heavy and light chain class to inhibit this binding indicates that these results are more likely to be due to idiotypic cross-reactivity.

Cross-reactive idiotypes have been described in the sera of mice (13-19), rabbits (20-22), guinea pigs (23), and man (2434). Although there are numerous reports for such crossreactivities in animals, in man, fewer reports exist, and these have been predominantly amongst antibodies isolated from sera of individuals having autoimmune disease (24-33). The results of this study affirm the possibility that antibodies directed to external antigens may also share CRI.

One reason for the production of CRI could be the presence of a limited number of antigenic epitopes on casein. This factor may be involved in the sharing of idiotypes observed amongst anti-thyroglobulins $(30,34)$ and anti-ssDNA antibodies (31). The number of antigenic epitopes on bovine casein is unknown, but since casein is a family of proteins of varying molecular weights $(12,000-24,000)$ with a range of electrophoretic mobilities (35), it appears improbable that epitope restriction could be responsible for the cross-reactivities observed here.

Another reason for the observed cross-reactive idiotypes could involve the nature of the patients studied. Since IgAdeficient individuals already share defects in IgA production, it is possible that certain $\mathrm{V}$ restrictions linked to this defect could be present. In addition, it is known that HLA A1, B8, and particularly DR3 are present in increased frequency in IgA-deficient individuals (36). One might speculate that the genetic expression of this DR locus could be associated with particular $V_{\mathbf{H}}$ genes governing selected idiotypic determinants. Studies to determine whether this is true in the population studied here are underway; however, of the two North American IgA-deficient donors who shared CRI (using the autologous reagent), neither were HLA, B1, B8, or DR3, nor did they share any common DR type.

In summary, this data shows that antibodies of similar specificity, isolated from IgA-deficient human sera, can share CRI and that sharing of CRI is particularly common for Finnish donors. The reasons for this restriction of immunoglobulin heterogeneity are unknown, but this system may be useful in the elucidation of $\mathrm{V}$ region inheritance in man.

\section{Acknowledgments}

The authors wish to thank Dr. G. Litman for the gift of myeloma sera, Dr. R. Geha for the gift of anti-human antitetanus antibody, Dr.
H. Farrell for the purified sodium caseinate, Ms. Carol Meehan for technical assistance, and the staff of the Immunodeficiency Clinic for continued supportive care of the patients.

This work was supported by grants AI-15809, CA-19267, and CA29502 from the U. S. Public Health Service, grant ACS IM-245 from the American Cancer Society, and by contributions from The Beneficial Corp. and the Zelda R. Weintraub Cancer Fund.

\section{References}

1. Cunningham-Rundles, C. 1982 . Naturally occurring autologous antiidiotypic antibodies. J. Exp. Med. 155:711-719.

2. Buckley, R. H., and S. C. Dees. 1969. Correlation of milk precipitins with IgA deficiency. $N$. Engl. J. Med. 281:465-469.

3. Cunningham-Rundles, C., W. E. Brandeis, R. A. Good, and N. K. Day. 1978. Milk precipitins and circulating immune complexes and IgA deficiency. Proc. Natl. Acad. Sci. USA. 15:3387-3389.

4. Cunningham-Rundles, C., W. E. Brandeis, R. A. Good, and N. K. Day. 1979. Bovine proteins and the formation of circulating immune complexes in selective IgA deficiency. J. Clin. Invest. 64:272279.

5. Cunningham-Rundles, C., W. E. Brandeis, R. Safai, R. O'Reilly, N. K. Day, and R. A. Good. 1979. Selective IgA deficiency and circulating immune complexes containing bovine proteins in a child with chronic graft vs. host disease. Am. J. Med. 67:883-889.

6. Cunningham-Rundles, C. 1981. The identification of specific antigens in circulating immune complexes by an enzyme-linked immunosorbant assay: detection of bovine $\alpha$-casein IgG complexes in human sera. Eur. J. Immunol. 11:504-509.

7. Klaus, G. G. B. 1978. Antigen-antibody complexes elicit antiidiotypes. Nature (Lond.) 272:255-256.

8. Turner, M. W., H. H. Bennich, and J. F. Natvig. 1970. Pepsin digestion of human G-myeloma proteins of different subclasses. I. The characteristic features of pepsin cleavage as a function of time. Clin. Exp. Immunol. 7:603-625.

9. Theofilopoulous, A. N., C. R. Wilson, and F. J. Dixon. 1976. The Raji cell radioimmune assay for detection of immune complexes in human sera. J. Clin. Invest. 57:169-182.

10. Geha, R. S., and R. P. Weinberg. 1978. Anti-idiotypic antisera in man. I. Production and immunochemical characterization of antiidiotypic antisera to human antitetanus antibody. J. Immunol. 121: 1518-1523.

11. Michaelsen, T. E., R. Geha, and J. B. Natvig. 1971. Isolation and characterization of IgG subclasses proteins and $\mathrm{Fc}$ fragments from normal human IgG. Immunochemistry. 8:235-242.

12. Jorgensen, T., G. Gaudernack, and K. Hannestad. 1977. Production of BALB/c anti-idiotypic antibodies against the BALB/c myeloma protein 315 does not require an intact ligand-binding site. Scand. J. Immunol. 6:311-318.

13. Sy, M. S., A. Brown, B. A. Bach, B. Benacerraf, P. D. Gottlieb, A. Nisonoff, and M. I. Greene. 1981. Genetic and serological analysis of the expression of cross-reactive idiotypic determination on anti-pazobenzenarsonate antibodies and p-azobenzenarsonate specific suppressor T-cell factors. Proc. Natl. Acad. Sci. USA. 78:1143-1147.

14. Rothstein, A. M., J. D. Benedetto, R. L. Kirsch, and M. L. Gefter. 1980. Unique determinants associated with hybridoma proteins expressing a cross-reactive idiotype: frequency among individual immune sera. J. Immunol. 125:1987-1992.

15. Marchalonis, J. J., G. W. Warr, P. Smith, G. S. Regg, and F. J. Morgan. 1979. Structural and antigenic studies of an idiotype bearing murine antibody to the arsonate hapten. Biochemistry. 18: $560-565$

16. Sakato, N., and H. Eisen. 1975. Antibodies to idiotypes of isologous immunoglobulin. J. Exp. Med. 141:1411-1426.

17. Benjamin, C. D., A. Miller, E. E. Sercarcz, and M. A. Harvey. 1980. A predominant idiotype on anti-hen egg white lysozyme antibodies from diverse mouse strains. J. Immunol. 125:1018-1025. 
18. Rose, L. M., M. Goldman, and P. H. Lambert. 1982. The production of anti-idiotypic antibodies and of idiotype anti-idiotype immune complexes after polyclonal activation induced by bacterial LPS. J. Immunol. 128:2126-2133.

19. Claflin, L., and J. M. Davie. 1975. The clonal nature of the immune response to phosphorycholine (PC). V. Cross-idiotypic specificity among heavy chains of murine anti-PC antibodies and PCbinding myeloma proteins. J. Exp. Med. 140:673-686.

20. Rodkey, L. S. 1974. Studies of idiotypic antibodies. Production and characterization of auto-anti-idiotypic antisera. J. Exp. Med. 139: 712-720.

21. Yarmush, M., J. A. Sogn, M. Mudgett, and T. J. Kindt. 1977. The inheritance of idiotype to immunoglobulin allotypes. J. Exp. Med. 145:916-930.

22. Binion, S. B., and L. S. Rodkey. 1982. Naturally induced autoanti-idiotype antibodies. J. Exp. Med. 156:860-872.

23. Shafer, K. E., and C. J. Bellone. 1980. Extensive cross-reactive idiotypes among guinea pig anti-TMA antibodies. Scand. J. Immunol. 12:203-212.

24. Geltner, D., E. C. Franklin, and B. Frangione. 1980. Antiidiotypic activity in the IgM fractions of mixed cryoglobulins. $J$. Immunol. 125:1530-1535.

25. Kunkel, H. G., V. Agnello, F. G. Joslin, R. J. Winchester, and J. D. Capra. 1973. Cross idiotypic specificity among monoclonal IgM proteins with anti-gammaglobulin activity. J. Exp. Med. 137:331-342.

26. Williams, R. C., H. G. Kunkel, and J. D. Capra. 1968. Antigenic specificities related to the cold agglutinin activity of gamma M globulins. Science (Wash. DC). 161:379-381.

27. Abraham, G. N., D. N. Podell, E. H. Welch, and S. L. Johnston. 1983. Idiotypic relatedness of human monoclonal IgG cryoglobulins. Immunology. 48(2):315-320.
28. Lefvert, A. K., R. W. James, C. Alliod, and B. W. Fulpius 1982. A monoclonal anti-idiotypic antibody against anti-receptor antibodies from myasthenic sera. Eur. J. Immunol. 12:790-792.

29. Altevogt, P., and H. Wigzell. 1983. VH-associated idiotype in human anti-thyroglobulin antibodies. Scand. J. Immunol. 17(2):183192.

30. Matsuyama, T., J. Fukimori, and H. Tanaka. 1983. Evidence of unique idiotypic determinants and similar idiotypic determinants on human anti-thyroglobulin antibodies. Clin. Exp. Immunol. 51: (2)381-386.

31. Solomon, G., J. Schiffenbauer, H. D. Keiser, and B. Diamond. 1983. Use of monoclonal antibodies to identify shared idiotypes on human antibodies to native DNA from patients with systemic lupus erythematosus. Proc. Natl. Acad. Sci. USA. 80(3):850-854.

32. Tachovsky, T. G., M. Sandberg-Wollheim, and L. G. Baird. 1982. Rabbit anti-human cerebrospinal fluid IgG. I. Characterization of anti-idiotypic antibodies produced against MS cerebrospinal fluid. J. Immunol. 129(2):764-770.

33. Førre, $\varnothing$, J. B. Natvig, and T. E. Michaelson. 1977. Crossidiotypic reactions among anti-Rh(D). Scand. J. Immunol. 6:9971003. (Abstr.)

34. Nye, L., L. C. Pontes De Carvalho, and I. M. Roitt. 1980. Restriction in the response to autologous thyroglobulin in the human. Clin. Exp. Immunol. 41:252-263.

35. Whitney, R., J. R. Brunner, K. E. Ebner, H. M. Farrell, R. V. Josephson, C. V. Moor, and H. E. Swaisgood. 1976. Nomenclature of the proteins of cow's milk: 4th revision. J. Dairy Sci. 59:795-815.

36. Hammarstrom, L., and C. I. E. Smith. 1983. HLA-A, B, C and DR antigens in immunoglobulin A deficiency. Tissue Antigens. 21:75-79. 